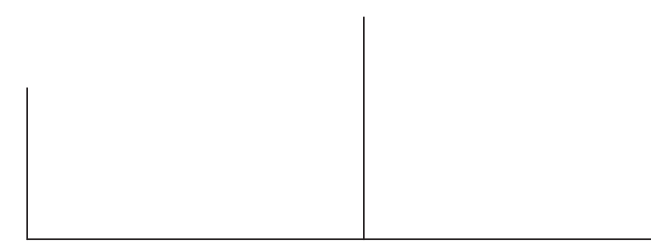

Rev. Latinoam. Psicopat. Fund., III, 2, 26-41

\title{
O superego: em busca de uma nova abordagem*
}

\author{
Marta Rezende Cardoso
}

\begin{abstract}
Este artigo apresenta a proposição de uma nova concepção do superego, segundo a qual os imperativos superegóicos seriam comparáveis, em todos os indivíduos, a um "enclave psicótico".

Trata-se aqui de aprofundar aspectos fundamentais da questão do superego, numa tentativa de elaborar alguns pontos que ficaram problemáticos em Freud, Melanie Klein e outros autores pós-freudianos.

A obra de Jean Laplanche foi útil como fonte principal na formulação das hipóteses apresentadas cuja incidência na clínica psicanalítica parece inegável.
\end{abstract}

Palavras-chave: Superego, "intraduzível”, culpabilidade, ideais

* Tradução de Pedro Henrique Bernardes Rondon (SPCRJ). 


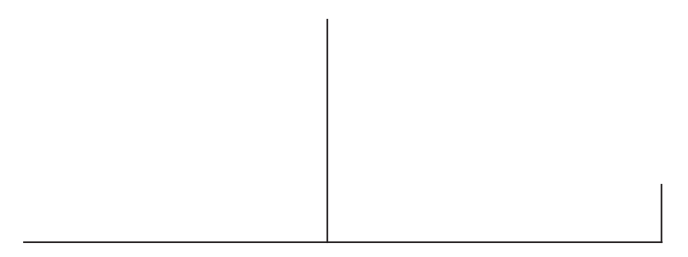

Ao longo de nossa prática de psicanalista, com freqüência somos interpelados pela questão do superego, que tem sempre forte incidência sobre o conjunto da psicopatologia, atingindo igualmente determinados aspectos essenciais de toda prática clínica, em especial o problema de seus impasses.

Dada a importância do tema do superego, tanto no que se refere à metapsicologia e à psicopatologia, quanto a suas implicações no campo do tratamento, pareceu-nos decididamente proveitoso que nos dedicássemos a estudá-lo. É nosso propósito, portanto, pôr mãos à obra nessa problemática.

A dupla faceta do superego - interditor e pulsional - está reunida na hipótese clássica de um herdeiro do complexo de Édipo. Já na trajetória freudiana encontramos, de um lado, a idéia de um representante da realidade; de outro, a de um superego - instância que extrai das pulsões a sua força.

As dificuldades que surgem com base nesse paradoxo parecem-nos ligadas à própria evolução dessa teoria, aos seus desenvolvimentos e aos seus desvios, a questão endógeno-exógeno representando aqui importante papel. Acompanhando Freud em suas hesitações quanto ao conceito do superego, chamaram nossa atenção as contradições de sua teoria. 


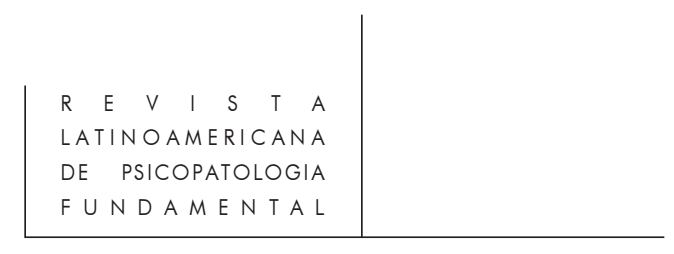

A questão da dupla polaridade do superego na realidade se prenuncia bem cedo na teoria de Freud, ainda que só na última parte de sua obra vá tornar-se mais explícita, sob a influência de Melanie Klein (Freud 1930; p. 317).

Apesar das oscilações teóricas de Freud, apesar das formulações de Melanie Klein que evidenciaram o caráter "sádico" do superego, ou das formulações de Lacan que fala de um superego "feroz e obsceno" (Lacan 1966; p. 434), a idéia de um superego como instância da ordem moral ainda predomina na psicanálise.

Apesar das numerosas observações clínicas que mostram uma tirania do superego - tirania que não pode estar relacionada às interdições parentais e sociais -, ainda continua presente essa estranha evidência na teoria: o superego seria necessariamente uma instância interditora inconsciente e seria construída, ao menos num de seus aspectos, por meio de uma interiorização dessas interdições.

Fenômenos como a autopunição, a culpa, a compulsão à repetição, a reação terapêutica negativa, entre outros, põem em questão para nós o papel do superego na vida psíquica. Além disso, esses temas vêm entrecruzar-se, seja na teoria psicanalítica, seja nas situações clínicas, mas a nosso ver o problema de sua articulação precisa ser mais examinado.

Como conciliar a função moralizante do superego com seu caráter pulsional, sádico? De que "realidade" o superego seria o representante? Quais são as relações entre o superego, o ego e o id? Será que o superego tem originariamente um conteúdo moral?

Visando à elaboração dessas questões, vamos, num primeiro momento, dedicar nossa atenção a certos desenvolvimentos de Freud e Melanie Klein. Num segundo momento, apresentaremos as linhas gerais de nossas próprias hipóteses, cuja principal orientação tem sido a "teoria da sedução generalizada" de Jean Laplanche.

\section{Uma teoria paradoxal do superego}

\section{Abordagem freudiana}

Conceituado somente em 1923, com a publicação do artigo "O ego e o id", o superego emerge de fato tardiamente na obra de Freud. Surge, entretanto, em continuidade direta com a noção de "consciência moral" (autocensura) e com a instância do ideal do ego (Freud, 1923).

O superego será concebido como uma instância responsável, ao mesmo tempo, por diversas funções e é em seu seio que Freud vai tentar integrar as várias dimensões que balizara anteriormente. Vai terminar por atribuir ao superego três funções: a auto-observação, a consciência moral e a "base de apoio" dos ideais (Freud, 1923; p. 93). 


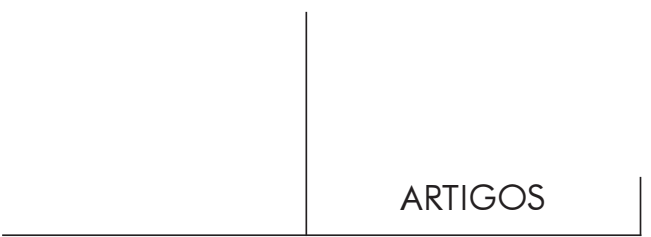

É preciso examinar, na obra freudiana, uma dinâmica que põe em jogo pelo menos dois pólos que participam da gênese do superego. De um lado, pela via da consciência moral e da autocensura, encontramos o pólo da interdição; de outro, o pólo do ideal. Porém, ainda que encontremos em sua obra a existência desses dois pólos, isso não significa que Freud os tenha articulado bem.

Nós propomos introduzir ainda um terceiro pólo na gênese do conceito de superego em Freud, pólo mais obscuro, menos desenvolvido diretamente e que, na nossa opinião, comporta em si mesmo os aspectos mais essenciais: trata-se do ataque pulsional, problemática que, de acordo com a nossa visão, não deveria ser confundida com a problemática da interdição. Não é a interdição externa que vai ser determinante aqui, mas sim a reivindicação pulsional em si mesma, em seus aspectos sexuais desligados, lesivos ao ego.

A questão do superego se situa numa trama de conceitos, em que a virada provocada pela introdução do narcisismo ocupa lugar fundamental (Freud, 1914). Essa virada, na qual a psicose tem papel central, vai resultar na construção de uma segunda teoria das pulsões, e de um novo modelo tópico.

A dimensão persecutória do superego, dimensão que parece-nos central no funcionamento dessa instância, está nitidamente indicada por Freud. Na apresentação formal do superego, este será concebido como uma instância de observação, como uma parte separada do ego, que exerce vigilância sobre a outra.

Até o fim de sua obra, Freud vai reafirmar ainda essa dimensão de vigilância ligada ao superego e vai considerá-la, ainda então, como uma de suas funções essenciais. Freud continua a reconhecer na psicose o campo no qual a emergência do superego está ancorada (Freud, 1933; pp. 83-84).

Na genealogia desse conceito, a psicose paranóica não é o único referencial. A melancolia é também importante fonte clínica. Trata-se uma vez mais da ação de uma autocensura cujo caráter é exacerbado. Neste fenômeno reencontramos a violência e a ferocidade dessa instância que vigia o ego. É a instância de observação - a consciência moral - que perpetua uma crítica originariamente vinda do exterior (Freud, 1917; p. 266).

Os sintomas da melancolia são engendrados pela ação de uma culpabilidade que, por sua vez, resulta da identificação com o objeto perdido. As violentas recriminações que uma parte do ego dirige à outra são, de fato, dirigidas ao objeto. É a sombra do objeto que, incorporada ao ego, vai julgá-lo com violência. Quais são, porém, os fundamentos dessa força de ataque do objeto, de sua força "demoníaca"?

O processo de identificação apresenta-se aqui numa modalidade toda especial. $\mathrm{Na}$ "identificação com o objeto perdido", uma parte do objeto - a parte "má" - não será integrada ao ego. Ao contrário: o ego será atacado por ela, de dentro, uma parte do ego tornando-se, dessa maneira, o carrasco da outra. O problema do masoquismo, portanto, está no centro da temática do superego. Trata-se aqui de 


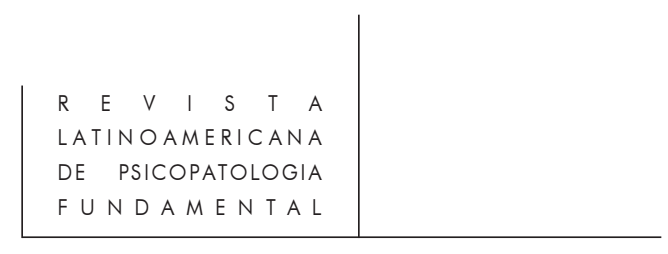

um retorno do objeto sobre si mesmo, do "transporte" para si mesmo, da face que ataca do objeto: os aspectos des-ligados são colocados no interior.

Observemos igualmente que os desenvolvimentos precedentes de Freud sobre a neurose obsessiva tinham trazido para o primeiro plano o caráter esmagador e pulsional da consciência moral. Trata-se de uma doença centrada na moral, nas autocensuras. O conflito moral, aqui, é torturante, implacável. A dimensão do sadomasoquismo é introduzida na problemática da moral, o que de fato vem abrir a questão de uma conjunção fundamental entre castigo e gozo.

Desse modo, a dupla polaridade do superego (linguagem da lei e aspecto pulsional, sádico) já estava anunciada. O caso do "Homem dos ratos", a este propósito, é muito rico sob diversos aspectos. Salientemos em especial o "suplício dos ratos", conotando simultaneamente castigo e gozo - o que, aliás, Freud não deixou passar em branco (Freud, 1909; p. 208).

A noção do superego virá finalmente cruzar a de pulsão de morte, e o retorno de uma dimensão de des-ligação na teoria freudiana vai influenciar diretamente o estudo do superego. A propósito deste ponto, nossa atenção se volta, em especial, para os desvios que a emergência da pulsão de morte pode ter feito nascer na teoria de Freud.

A pulsão de morte é uma noção que coloca questões importantes. Jean Laplanche indicou um proveitoso caminho para problematizá-la. Segundo este autor, essa noção teve papel central num movimento de transformação da teoria freudiana, movimento que constitui importante desvio - o da "dessexualização" da sexualidade. Esta tendência consistiu num "extravio biologizante" da sexualidade (Laplanche, 1993; p. 117).

A sexualidade ficará reduzida ao seu lado de ligação, sendo o auto-ataque atribuído à destrutividade. É aí, para Freud, que está o fundamento da pulsão de morte cuja origem ele supõe ser interna. ${ }^{1}$ Porém, a dupla injunção do superego - na qual estão em jogo simultaneamente des-ligação e alteridade - certamente denuncia as dificuldades próprias a essa teoria endogenética.

Se, a esse propósito, não encontramos em Freud solução satisfatória, a temática do superego vem, não obstante, exigir reflexão sobre essa questão. O aspecto contraditório de sua concepção incita-nos a examinar a questão de interno-externo na constituição da pulsão. Este eixo está situado no cerne da problemática do superego.

1. Para Laplanche, tratar-se-ia da "pulsão sexual de morte" (des-ligação), que se opõe à "pulsão sexual de vida" (ligação): "Trata-se, no entanto, de uma distinção no regime econômico das pulsões, em sua maneira de trabalhar; somente a partir daí é que é possível conceber-se uma única e mesma libido em ação nos dois tipos de pulsões" (Laplanche, 1981; p. 259). 


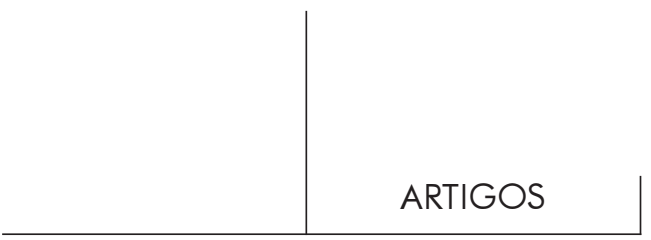

A ameaça de uma sexualidade não-ligada vai se transpor em ameaça de castração, transposição correlativa à passagem do Édipo e da figura paterna para o primeiro plano da teoria freudiana. Não obstante, ainda que tendendo a eclipsar-se dessa maneira, a dimensão do originário vai deixar um resto nessa teoria. As oscilações e paradoxos da conceituação freudiana do superego mostram os sinais disso.

Abordagem kleiniana

A teoria de Melanie Klein que, de maneira decisiva, insistiu nos aspectos destrutivos do superego, não deixou Freud indiferente e ele vai levar em conta suas contribuições. Entretanto, não podemos deixar de lado a observação de que no próprio Freud, bem antes de Melanie Klein, se encontram indícios muito interessantes a propósito da face pulsional do superego. De uma certa maneira, a teoria kleiniana constitui um desenvolvimento das aberturas apontadas por Freud.

Em Melanie Klein, o superego torna-se nitidamente arcaico, pulsional e feroz. A autora traz efetivamente uma nova perspectiva de análise: o ataque pulsional vai finalmente assumir aí um estatuto crucial.

A concepção kleiniana do superego resulta justamente do privilégio atribuído à singularidade do mundo interior. Constatando a oposição ou o contraste entre a severidade que o superego pode desenvolver, e a tolerância dos pais, essa concepção supõe que a formação do superego não seria calcada sobre as interdições parentais. Não se trata aqui dos pais reais, mas sim de uma imago que se constitui no interior do psiquismo (Klein, 1933; p. 299).

As fantasias agressivas da criança são projetadas sobre os pais. É assim que se constrói uma imagem fantástica e deformada das pessoas que a circundam. Uma vez que o mecanismo de introjeção funciona ao mesmo tempo, essas imagos irreais são, então, interiorizadas. A criança se sente governada por pais perigosos e cruéis: é o superego agindo em seu interior.

É preciso, entretanto, saber que em Klein o ataque pulsional é um equivalente estrito da agressividade. Esta concepção constitui, de fato, um "aprofundamento" da oposição freudiana entre pulsão de morte e pulsão sexual.

Segundo Klein, o superego retira sua força totalmente do sadismo do id, força que ela considera "biológica". Uma vez que o caráter atacante e feroz do superego provém da força das pulsões, as raízes pulsionais das interdições superegóicas são, portanto, reconhecidas por ela. A questão da interdição moral fica, enfim, nitidamente secundarizada, o que só se torna possível aqui porque a alteridade não é central nesse sistema teórico.

O Édipo, no sentido estrito freudiano, fica também secundarizado. Não obstante, dado que o Édipo, ainda que transformado, emerge para Klein muito mais cedo, o superego que ela propõe continua sendo, então, um superego edipiano. Po- 


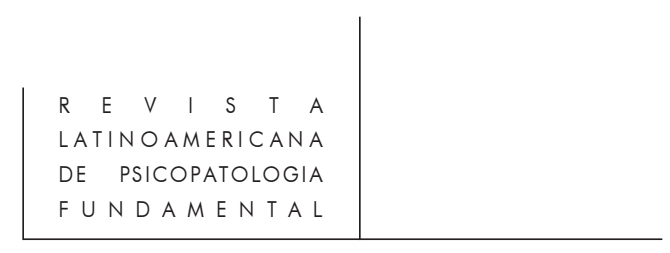

rém, ao considerar os personagens do Édipo como personificações das próprias pulsões do sujeito, ela vem modificar consideravelmente a perspectiva freudiana (Klein, 1945; p. 411).

Nos casos de fixação do superego às fases iniciais de sua formação, os mecanismos psicóticos vão dominar o funcionamento psíquico. Se as tendências agressivas da criança não diminuem, as imagos irreais e aterrorizantes não podem reduzir-se e vão impedir que as tendências genitais ganhem mais força. Estas últimas trariam imagos benéficas, protetoras, mais próximas da "realidade".

Vemos que na teoria kleiniana o superego termina portanto por alcançar, embora secundariamente, um caráter ético e moral. É a transformação do "superego perseguidor" num "superego legislador", passagem que vem evocar a culpabilidade e a idéia de uma síntese (Klein, 1934; p. 310). O "superego legislador" teria, dessa maneira, de ser situado num registro secundário, formulação sem dúvida interessante, mas que não soluciona o problema do "paradoxo" do superego.

No sistema kleiniano, o superego tenderá, portanto, a apresentar um duplo caráter - superego "mau" e superego "bom" -, sendo que este está diretamente ligado à culpa reparadora. A relação entre ataque pulsional e culpa mantém, assim, um caráter muito ambíguo, apesar das indicações de Klein que nos orientam para a idéia de uma articulação complexa.

32 A complexidade dessa passagem põe em questão o aparelho psíquico em seu conjunto. A este propósito, do nosso ponto de vista, os desenvolvimentos de Klein deixam ainda numerosas perguntas sem resposta.

\section{Superego e "mensagem enigmática"}

Reencontrar a dimensão não-totalizante e perversa da pulsão sexual é algo que desde então se revela indispensável para quem se dedica a analisar o conceito de superego. Nosso propósito é, portanto, tentar construir um modelo baseado nas dimensões da alteridade e da sexualidade. Uma vez que não compartilhamos da visão de um indivíduo fechado sobre si mesmo no início, por isso mesmo nos afastamos de uma visão endogenética.

O reencontro com a dimensão daquilo que é "estrangeiro" representa importante papel nas condições de emergência do superego, e este aspecto merece ser mais estudado. Nosso objetivo primordial também consiste em analisar esse tema desse ponto de vista.

O contraste entre a severidade do superego e a das proibições parentais, o caráter de ataque a si mesmo, aspecto "demoníaco" do superego, parecem-nos integrar-se mal numa concepção segundo a qual o superego seria uma instância egóica, constituída por identificação. É preciso tentar construir um modelo capaz de dar conta da singularidade do superego. 


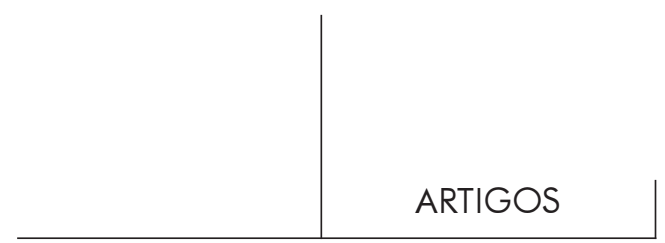

A teoria desenvolvida por Jean Laplanche é centrada na noção de enigma e baseia-se no primado da alteridade do outro e do sexual. Seguir este caminho revelase uma direção conseqüente para tentar superar as dificuldades próprias da questão do superego. Como o autor apontou, “... o primado do outro adulto na gênese do mundo pulsional da criança deveria, ao menos, permitir-nos retomar de outra maneira a questão: exógeno-endógeno" (Laplanche, 1994; p. 18).

A teoria da sedução generalizada, centrada na categoria de mensagens, parte da confrontação da criança com o adulto sedutor, confrontação com mensagens sexuais que são enigmáticas, porquanto o são para o próprio adulto. Assim fica assentado o fundamento de uma situação de passividade originária, com essas mensagens ultrapassando em larga medida as capacidades de domínio da criança "penetrada" pela sexualidade inconsciente do adulto. O modelo da tradução, mais exatamente o modelo do fracasso da tradução, demonstra-se de capital importância no seio dessa teoria. ${ }^{2}$

Jean Laplanche, a propósito do superego, propõe a pergunta seguinte: “... bloqueados entre os dois tempos do recalcamento originário, os imperativos do superego podem não ser recalcados. Não seria possível, então, considerá-los como uma espécie de 'enclaves psicóticos' de toda personalidade?” (Laplanche, 1990; p.129). Esta proposição constitui um ponto de partida na construção de nossas próprias idéias. $^{3}$

Analisar o superego com base nesse universo teórico permite-nos afirmar sua "condição de estrangeiro" na tópica. A categoria de mensagem e o modelo do recalcamento, eixos centrais da teoria da sedução generalizada, estão igualmente na base de nossas hipóteses.

Trata-se de ancorar a gênese do superego no recalcamento originário: mensagens enigmáticas que não podem ser metabolizadas ficam bloqueadas entre o primeiro e o segundo tempos, mensagens que vão então constituir enclaves na tópica. Para nós está aí o fundamento da formação do superego.

Considerar o superego como um "corpo estranho" rebelde ao esquema de metabolização-recalcamento, como um enclave, significa, por um lado, desprendêlo do sistema do ego; por outro, distingui-lo do recalcado, do id. Esta dupla conseqüência vem inaugurar uma outra direção na metapsicologia do superego. Voltaremos a isto.

É o mais exógeno, o mais "estrangeiro" na mensagem que vai ficar encravado na criança. Isso nos leva a conceber a idéia de uma transferência originária de mensagens enigmáticas singulares; mensagens irredutíveis, porquanto dificilmente

2. Para uma visão de conjunto da obra de Laplanche, ver Scarfone, 1997.

3. Para um aprofundamento desta abordagem, ver Cardoso, Marta R., 1995. 


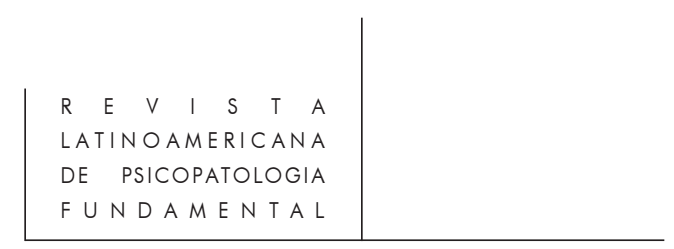

suscetíveis de serem remetidas a uma outra coisa; "mensagens-vereditos" que o indivíduo deverá imperativamente adotar sem que, para tanto, possa fazê-las suas, metabolizá-las ou recalcá-las.

A intrusão dessas mensagens engendra uma espécie de curto-circuito da comunicação; essas mensagens, cujo código de tradução parece estar fechado, ainda que sendo dirigidas à criança, estão paradoxalmente centradas - e de maneira cristalizada - sobre aquele que as emite. Retorno inquietante ao passado: com base em sua passividade originária a criança parece "sinalizar", sem o saber, os próprios enclaves do adulto - enclaves que lhe serão introduzidos à força. Freud já não nos dizia que o superego da criança se preenche com o mesmo conteúdo do superego parental?

A formação do superego, portanto, não nos parece ter uma natureza identificatória. A identificação é, por um lado, um processo que se opera na primeira pessoa; por outro lado, implica que possa ter lugar uma assimilação do outro. Ora, trata-se aqui justamente da impossibilidade de apropriar-se do outro, da impossibilidade, para o ego, tanto de integrar esse material quanto de recalcá-lo em seu território.

Tomando como paradigma o modelo do recalcamento, podemos supor duas modalidades distintas de seu fracasso: fracasso parcial e fracasso radical da tradução. O recalcado - o id - seria o resto deformado de uma tradução parcial das mensagens, enquanto a constituição do superego implicaria não uma deformação recalcante, mas sim mensagens que não chegam a entrar no processo de tradução. Estas mensagens, não podendo ser recalcadas nem substituídas por outra coisa, ficam "bloqueadas no mesmo lugar".

Supor a idéia de uma impossibilidade tanto de recalcar quanto de traduzir determinadas mensagens absolutamente não implica considerar a exclusão, desses elementos, para fora do aparelho psíquico. É no superego que propomos inscrevêlos. Já é tempo de tentar extrair as consequiências metapsicológicas dessa "inquietante estranheza" do superego, tão flagrante na genealogia desse conceito, quanto na clínica psicanalítica.

Situando o superego do lado do ataque e situando sua gênese nas origens da vida psíquica, é preciso também levar em conta os mecanismos arcaicos aos quais o ego, para poder "encará-lo", se vê forçado a recorrer.

Diante da impossibilidade de traduzir e de des-traduzir, o sistema do ego transborda. Esse transbordamento corresponde, de fato, à ação da des-ligação, esta última implicando não apenas que o sistema egóico seja transtornado, mas também que o ego volte contra si mesmo os aspectos que o atacam. O ego aqui é passivo em relação ao superego, em relação a esse representante da "realidade da mensagem".

Diante do superego, o ego teme a invasão do "mau", essa sombra do objeto que, caindo sobre ele, põe em perigo a eficácia de suas fronteiras. O paradigma aqui é a ameaça da perda do amor, ameaça não somente de ser privado do objeto, 


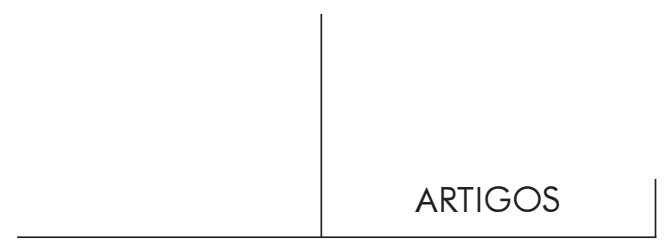

mas também de se achar exposto ao seu lado demoníaco. Ocupado por uma força radicalmente estrangeira diante da qual não há sequer a possibilidade de uma formação de compromisso, o ego é compelido a agir a partir de um imperativo "estrangeiro", modalidade paradoxal de defender-se, de "responder".

É certo que “... o pequeno ser humano, que não está em condições de fazer isso, tem que responder a mensagens impregnadas de sexualidade. Esta resposta, essas respostas, são autoconstruções suas, poderíamos dizer sua "ptolomeização"' (Laplanche,1994a; p. 29).

$\mathrm{Na}$ origem, essa resposta é, por definição, sempre inadequada, uma vez que se trata de uma tradução inevitavelmente imperfeita que, portanto, deixa restos para trás: as "representações-coisas". É lá que se situa, seguindo a perspectiva que a teoria da sedução nos abre, o recalcamento originário, a constituição do inconsciente.

Por nossa parte, trabalhando a questão do superego, dirigimo-nos para aquilo que estaria aquém de um fracasso de tradução, para a constituição de um "corpo estranho" rebelde, resultante de uma recusa e de tradução e des-tradução - mensagens imóveis, impossíveis de decompor. A propósito da relação ego-superego tentamos, assim, estudar a idéia de uma via de "resposta" diferente daquela aberta pelo esquema da metabolização-recalcamento.

O mais "estrangeiro" só se torna um "rejeitado" para o ego - ou segundo o ponto de vista do ego. Aquilo que está, por assim dizer, "forcluído" não pode deixar de ter um lugar preciso no aparelho psíquico. O superego seria constituído por uma espécie de "coleção" de mensagens enigmáticas impossíveis de metabolizar.

\section{Superego e culpa}

Ao ancorar a gênese do superego no recalcamento originário, tentamos destacálo do cenário edipiano; o Édipo e a castração já são formações secundárias cuja função é de ligação.

Contrariamente a uma concepção da gênese do superego que se tornou clássica em psicanálise, tentamos demonstrar que essa gênese não remete àquilo que é secundário. Assim, empenhamo-nos numa retomada da tópica freudiana, especialmente no que se refere à questão do superego.

A passagem à moralidade, na verdade, diz respeito à ação do ego. Analisar a questão do superego com base na perspectiva do recalcamento secundário significa, mais precisamente, examinar as novas possibilidades e os limites da ação defensiva do sistema do ego em relação ao superego. Amarrar, de maneira intrínseca, o problema do superego a uma dimensão de moralidade, não nos parece algo evidente.

Neste sentido, nossas idéias se opõem à concepção segundo a qual a origem do superego teria de ser situada ao mesmo tempo no originário e no secundário. 


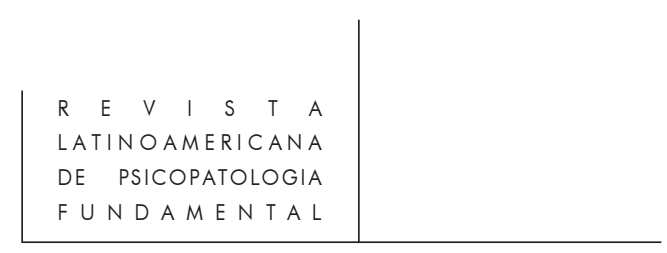

Tentar resolver esse problema por meio da dicotomia superego "mau"/superego "bom", no nosso modo de ver, não se revela uma verdadeira solução. Seguir essa direção implicaria o risco de continuar a reproduzir o trabalho do ego na própria teoria. Dito isto, a expressão "superego edipiano" não tem como nos convir; no máximo ela pode servir para descrever o trabalho das instâncias egóicas ante o superego, mas não aquilo que é da ordem da gênese do superego em si mesma.

A noção de culpabilidade, noção cujas ambigüidades em relação à situação tópica tentamos superar aqui, é também uma formação secundária, mesmo no caso de uma culpa inexorável: "seja como for, és culpado".

A angústia de perseguição, a angústia de passividade em relação à "realidade da mensagem", situa-se necessariamente aquém da culpa. Afastando-nos de qualquer visão endogenética, só podemos criticar a idéia de uma culpabilidade originária. Se a culpa é, como nos diz Jean Laplanche, uma primeira maneira de concluir um pacto com a angústia, não seria ela uma forma, ainda que elementar, de resposta ao ataque, "resposta a uma perseguição inominável, sádica?" (ibid.; p. 27).

A angústia dita moral já é uma atitude do ego no sentido de "encarar" a invasão do "mau". Pela via da moralidade, não estaríamos passando do "responder a" para o "responder por", isto é: “... que foi que eu fiz para que você me tratasse dessa maneira, qual é a minha responsabilidade em tudo isso?" (ibid.; pp. 26-27).

Ante os imperativos morais categóricos, o indivíduo se vê ainda confrontado com a questão do poder sexual do outro, versão secundária da mesma questão. Esses imperativos, totalmente "imóveis", impossíveis de metabolizar, ficam marcados com o selo da condição de estrangeiros. Estamos pensando, aqui, nos aspectos da vigilância do superego, aspectos persecutórios cujas imagens da "voz da consciência", do "olho de Deus", são tão eloqüentes. Mas trata-se aí, de fato, do registro secundário das representações egóicas, representações que recobrem e, ao mesmo tempo, insinuam a "realidade" das mensagens introduzidas à força, mensagens persecutórias, porquanto impossíveis de metabolizar.

Assim, o superego não pode ser vinculado, de maneira intrínseca, a uma dimensão de moralidade. Somente o ego é que pode, pela via do recalcamento secundário, edipiano, fazer do superego um interditor, um juiz, implacável às vezes, das pulsões. A dicotomia superego pré-edipiano/superego edipiano fica ultrapassada, dessa maneira.

\section{O superego e os ideais}

A problemática dos ideais é extensa demais para poder ser apresentada sem exigir um estudo dela mesma. Dessa maneira, não vamos procurar abordá-la, por receio de termos de simplificá-la abusivamente para forçá-la a caber no quadro deste nosso trabalho. Vamos, portanto, limitar-nos a apresentar algumas indicações. 


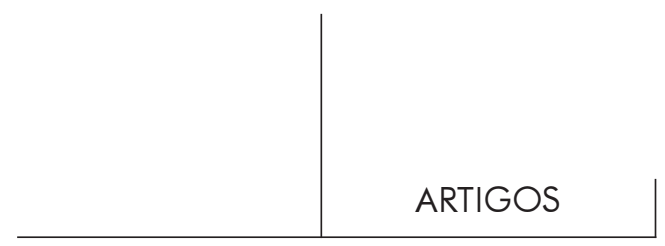

A propósito da relação entre o superego e o ideal do ego, propomos a idéia de um "contraponto" que poria em jogo, de maneira mais ou menos harmoniosa, uma dimensão de ataque e uma dimensão de simbolização no interior de um par heterogêneo: a idéia de uma similaridade entre essas duas noções está fora dos nossos propósitos.

Ao destacar o superego das outras instâncias do aparelho psíquico, queremos enfatizar, dentre outras coisas, que a gênese do superego e a das instâncias ideais são distintas. Para isso, temos de insistir ainda no fato de que não encaramos o superego como uma instância identificatória.

Quanto à constituição do superego, as nossas hipóteses avançam, antes, no sentido de uma espécie de "negativo" da identificação, os enclaves superegóicos dando-nos os sinais de uma impossibilidade de assimilar aquilo que vem do outro, ou seja, de uma impossibilidade de "fazê-lo seu".

Ao abordarmos os temas da lei e do poder, deveria ser-nos possível pôr em relação o superego com o ideal do ego, o que não significa reduzir essa relação a esta única dimensão. Dito isto, adiantamos a idéia de que superego e ideal de ego veiculam, na temporalidade do recalcamento secundário, duas ordens de "legalidade interna" bastante diferentes.

Do lado do superego, mediatizada pelo ego, temos uma ordem categórica que, portanto, não pode ser substituída por outra coisa; do lado do ideal do ego, o que temos é a abertura de uma nova dimensão identificatória, veiculando aspectos éticos, normativos - destinos da simbolização. Dessa forma, o ideal do ego se revela o verdadeiro herdeiro do complexo de Édipo.

Aproximar as instâncias ideais, egóicas, do superego, só faz obscurecer não apenas o lado que ataca e é des-ligado deste último, mas também as funções de ligação, mais ou menos elaboradas, próprias do ego ideal e do ideal do ego. Assim, se o estudo das instâncias ideais não foi elaborado diretamente, pensamos ter conseguido fazer ressaltar um aspecto essencial dessa questão, ao desprendermos o superego do sistema egóico.

Quanto à distinção entre o ego ideal e o ideal do ego, uma retomada do problema seria absolutamente indispensável. Esta questão, embora constituindo o objeto de vários trabalhos, ainda continua bastante obscura na teoria psicanalítica. No meu entender, o ego é um sistema portador de distintos aspectos; o ego ideal e o ideal do ego fazem parte desse sistema. A constituição destes últimos parece-nos referida à constituição narcísica nos níveis primário e secundário.

O recalcamento secundário revela-se uma via de abertura suscetível de efetuar uma certa "transformação" da relação entre ego e superego. O ideal do ego tem nela uma função simbolizadora essencial; sua constituição está ancorada no registro secundário. Na articulação que existe nesse "contraponto" do ideal do ego e do 


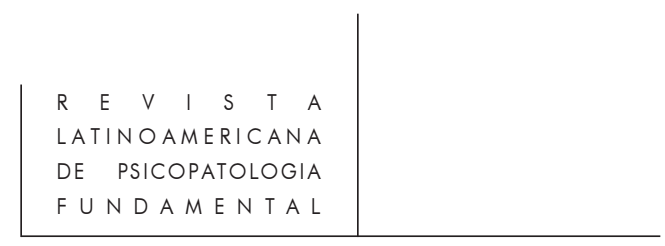

superego, acreditamos poder encontrar um dos elementos capazes de elucidar determinados fenômenos clínicos.

A título de ilustração, a seguir tentarei examinar sucintamente as modalidades de resposta próprias de determinadas patologias, nas quais o ego, limitado em sua capacidade de metabolização e de recalcamento, tende a utilizar mecanismos arcaicos. Esses métodos de defesa revelam, dentre outras coisas, a impotência do ego diante do superego, em especial a fragilidade da instância do ideal do ego. Mas é preciso igualmente observar que esses mecanismos são constituídos como métodos de ligação - derradeiras defesas - da força pulsional.

Como já mencionamos, nas situações clínicas (neuróticas e psicóticas), centradas numa auto-acusação violenta, esta, paradoxalmente, se configura como tentativa de defesa contra o risco de um afluxo pulsional de energia "des-ligada". O ego, defrontado com a impossibilidade de responder ao "excesso" de alteridade interna, faz o retorno dessa alteridade sobre si mesmo e passa a responder por ela.

No modelo da perversão, em especial no sadomasoquismo, o ego "transforma em seu contrário" uma situação de passividade absoluta diante do outro. A cena traumática assim é atuada, mas nesta vai-se repetir, de maneira compulsiva, uma recusa incessante: recusa da alteridade. $\mathrm{O}$ ego, cristalizado em sua vertente de onipotência narcísica (nível regido, portanto, pelo ego ideal), tenta aqui, a qualquer custo, exercer um suposto poder sobre esse outro interno.

Caberia aqui enfatizar que o caráter persecutório e dominador do superego não se confundiria com a idealização da onipotência própria do ego ideal. Esta já constitui uma tentativa de resposta aos imperativos superegóicos, às mensagens enigmáticas impossíveis de metabolizar.

Nesses exemplos, aos quais poderíamos acrescentar outros - incluído o modelo da paranóia -, o ego emprega operações defensivas primárias, assim como o retorno sobre si mesmo, a inversão, a negação e a projeção de uma alteridade radical interna - desses "enclaves psicóticos" - ,que nos parece povoar o campo do superego.

Entretanto, há também situações ditas normais, nas quais o superego não se apresenta de maneira feroz. Isso, a nosso ver, só é possível porque essa instância não dominou de maneira absoluta o funcionamento interno e porque a economia psíquica pôde contar com a atividade de um sistema egóico capaz de realizar modos de simbolização mais elaborados.

Isso significa que é necessário apelar também ao próprio pólo egóico para compreender situações patológicas. A este propósito, lembramos ainda que a questão do fracasso quanto a traduzir é indissociável da questão de um fracasso do narcisismo; estas duas noções são estritamente correlativas, o que implica termos sempre de interrogar o funcionamento de conjunto do aparelho psíquico.

Uma das contribuições de Jean Laplanche foi a de assinalar a complexidade da questão da ligação, ao mostrar, por exemplo, o caráter patológico daquilo que 


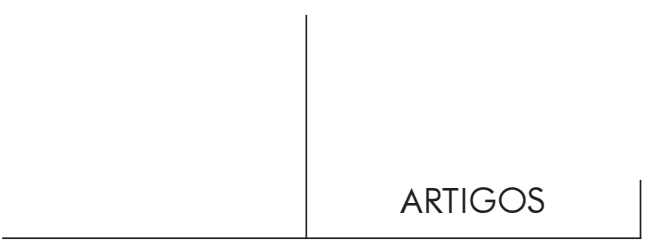

descreve como uma compulsão a "sintetizar”. “... o extremo da ligação é também o extremo da imobilização. (...) Há seguramente uma morte do psiquismo por desintegração, morte pela pulsão de morte, mas há também morte do psiquismo por enrijecimento e síntese excessivos, morte do psiquismo causada pelo ego" (Laplanche, 1990; p. 146).

Os aspectos mais arcaicos da ligação, assim como os mais elaborados, estão em constante interação, o que nos exigiria pensar sobre a polaridade ego ideal/ideal do ego. $\mathrm{O}$ funcionamento do sistema do ego resulta de uma dialética que se estabelece entre esses diferentes níveis de "tradução". Esta dialética efetivamente tem um lugar importante numa metapsicologia do superego, ponto deixado em aberto para um futuro estudo.

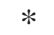

$* *$

Os caminhos abertos aqui estão longe de ter a pretensão de esgotar o assunto. Ao contrário, pensamos que eles deixam que se desdobrem diversas vias de reflexão. Por exemplo, as implicações desse modelo metapsicológico sobre o conjunto da psicopatologia, a ação das instâncias egóicas ante a "condição de estrangeiro" do superego, as articulações entre superego e ato de criação e, finalmente, os destinos do superego no tratamento psicanalítico.

Não vemos melhor maneira de concluir do que lembrando que uma pesquisa sobre questões metapsicológicas e psicopatológicas impõe esforço constante para que se chegue a formulações precisas. Isso obriga-nos a reexaminar nossas idéias permanentemente.

Com Laplanche pensamos que "a teoria psicanalítica pode reivindicar ser refutável e falsificável. O fato de que não utilize modelos físico-matemáticos não impede que tenha de submeter-se à prova do raciocínio e da confrontação com a experiência" (Laplanche, 1994b; p. 20).

Eis aí uma particularidade essencial desse campo teórico que só pode mesmo estimular-nos à prática clínica e à pesquisa em psicanálise. É nesta perspectiva que continuaremos a lançar-nos no estudo do superego.

Bibliografia

Freud, S. (1909). Remarques sur un cas de névrose obsessionelle. In Cinq psychanalyses.

Paris: PUF, 1992.

(1914). Pour introduire le narcissisme. In La vie sexuelle. Paris: PUF, 1977.

(1917). Deuil et mélancolie. In Oeuvres complètes. Paris: PUF, 1988, vol. XIII. 
(1923). Le moi et le ça. In Oeuvres complètes. Paris: PUF, 1991, vol. XVI.

(1930). Malaise dans la culture. In Oeuvres complètes. Paris: PUF, 1994, vol. XVIII.

(1933). La décomposition de la personnalité psychique. In Nouvelles conférences d'introduction à la psychanalyse. Paris: Gallimard, 1986.

KLeIN, M. (1927). Colloque sur l'analyse des enfants. In Essais de psychanalyse. Paris: Payot, 1972.

(1933). Le dévelopement précoce de la conscience chez l'enfant. In Essais de psychanalyse. Paris: Payot, 1972.

(1934). La criminalité. In Essais de psychanalyse. Paris: Payot, 1972.

(1945). Le complexe d'Oedipe éclairé par les angoisses précoces. In Essais de psychanalyse. Paris: Payot, 1972.

LaCAN, J. (1966). La chose freudienne. In Écrits. Paris: Seuil.

Laplanche, J. (1981). Problématiques IV - L'inconscient et le ça. Paris: PUF. (1987). Problématiques $V$ - Le baquet - transcendance du transfert. Paris: PUF. (1990). Nouveaux fondements pour la psychanalyse. Paris: PUF.

(1993). Le fourvoiement biologisant de la sexualité chez Freud. Paris: Synthélabo. (1994). Les forces en jeu dans le conflit psychique. Second International Conference "Jean Laplanche on psychic conflict". Londres/Canterbury.

(1994a). Responsabilité et réponse. In Cahiers de l'école de sciences philosophiques et réligieuses. Paris, Facultés Universitaires Saint-Louis, no 16.

(1994b). La psychanalyse comme anti-herméneutique. Communication présentée dans le cadre du Colloque de Cerisy, "Herméneutique: sciences, textes", Cerisy.

CARDoso, M. R. (1995). Surmoi et "théorie de la séduction généralisée". Universidade de Paris 7 - Denis Diderot, Paris. Tese de Doutorado.

SCARFone, D. (1977). Jean Laplanche. Paris: PUF.

\section{Resumos}

Este articulo presenta la proposición de una nueva concepción del superyo según la qual los imperativos superyoicos serían comparables, en todos los indivíduos, a un "enclavado psicótico".

Se trata de profundizar aspectos fundamentales de la question del superyo en una tentativa de elaborar algunos puntos dejados problemáticos en Freud, Melanie Klein y otros autores postfreudianos.

La obra de Jean Laplanche fué útil como fuente principal en la formulación de las hipóteses presentadas cuya incidencia sobre la clínica psicoanalítica parece innegable.

Palabras llave: Superyo, "intraducible", culpabilidad, ideales

Cet article présente la proposition d'une nouvelle conception du surmoi selon laquelle les impératifs surmö̈ques seraient comparables, chez tout individu, a une "enclave psychotique". 


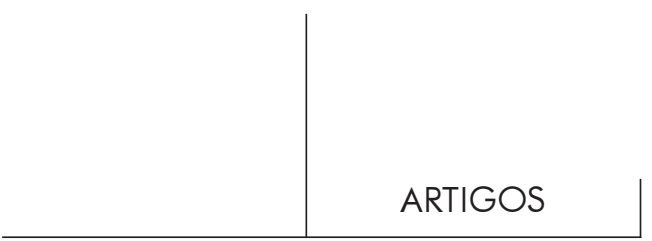

Il s'agit d'approfondir des aspects fondamentaux de la question du surmoi dans une tentative d'élaborer quelques points laissés problématiques chez Freud, Melanie Klein e d'autres auteurs postfreudiens.

L'oeuvre de Jean Laplanche a été utile comme source principale dans la formulation des hypothèses présentées dont l'incidence sur la clinique psychanalytique paraît indéniable.

Mots Clé: Surmoi, “intraduisible”, culpabilité, idéaux

This paper presents the proposition of a new conception of the superego in which the superego's imperatives would be comparable, in every individual, to a "psychotic enclave".

That's a matter of deepening some fundamental features of the issue of the superego, trying to work out some points left unresolved in Freud, Melanie Klein and other postfreudian authors.

The work of Jean Laplanche was useful as a main source in the formulation of the hypotheses that are presented, whose incidence in the psychoanalytical clinic seems undeniable.

Key words: Superego, "untranslatable”, culpability, ideals 